\title{
THE EFFECTS OF NATIONAL VACCINATION PROGRAM AND MASSIVE MIGRATION TO THE EPIDEMIOLOGY OF HEPATITIS A IN CHILDREN OVER THE PAST 5 YEARS
}

B. Cetin 1 , M. San², G. Mentes ${ }^{3}$.

${ }^{1}$ Ministry of Health, Cengiz Gökcek Maternity and Child Health Hospital, Pediatric Infectious Disease, Gaziantep, Turkey.

2Ministry of Health, Cengiz Gökcek Maternity and Child Health Hospital, Pediatrics, Gaziantep, Turkey.

${ }^{3}$ Ministry of Health, Cengiz Gökcek Maternity and Child Health Hospital, Microbiology, Gaziantep, Turkey.

\section{Background}

Acute hepatitis $A$ is a common public health problem in underdeveloped and developing countries. The hepatitis A vaccine has been implemented as part of the National Immunization Program in Turkey in November 2012. The aim of the present study was to investigate effects of the national vaccination program and massive migration on epidemiology and clinical burden of Hepatitis A infection.

\section{Methods}

This was a single center, retrospective chart review study among children diagnosed with viral hepatitis $A$ infection between 0 and 18 years of age from January 2013 to February 2018 in Gaziantep, Turkey. In addition to the admission time, age, nationality and gender information of all cases, the length of stay and direct medical cost of hospitalization were also evaluated in hospitalized cases.

\section{Results}

During study period total of 1039 cases were diagnosed with hepatitis A infection. Of these cases, $53 \%$ were males, 14\% were Syrian refugees and median age was 7.9 years. Number of cases per year (2013 through 2017) was $321,360,157,119$ and 73 respectively. The majority of the cases were detected in the November and December. While total number of cases were declining, we saw the number of Syrian children was increasing (Figure 1). Percentage of Syrian children in total cases in 2013 and 2017 was 6.5\% and $52.1 \%$ respectively (Figure 2). Mean hospitalization rate was \%49, median age in hospitalization group was 7.9 year and mean LOS was 4.84 days. and mean medical cost of hospitalization per case was $247 \$$.

\section{Discussion}

After implementing of the vaccine in the national program, case numbers are declining. But there is still susceptible individuals espicially in Syrian immigrants. In different studies seroroteciton for hepatitiis $A$ is between $\% 45$ - 84 in immigrants. In childrens these ratios are decreasing. In Turkey there are nearly 1,6 million Syrian children and $10 \%$ of them are in Gaziantep. Prioritizing vaccination of this susceptible group started in the middle of 2017 in our region. We expect these rates to decrease in the future.

While giving decision for hospitalization, non-compliance with guidelines or not trusting home-care can increase the hospitalization rates improperly. We organized seminars to the pediatricians to adress this issues.

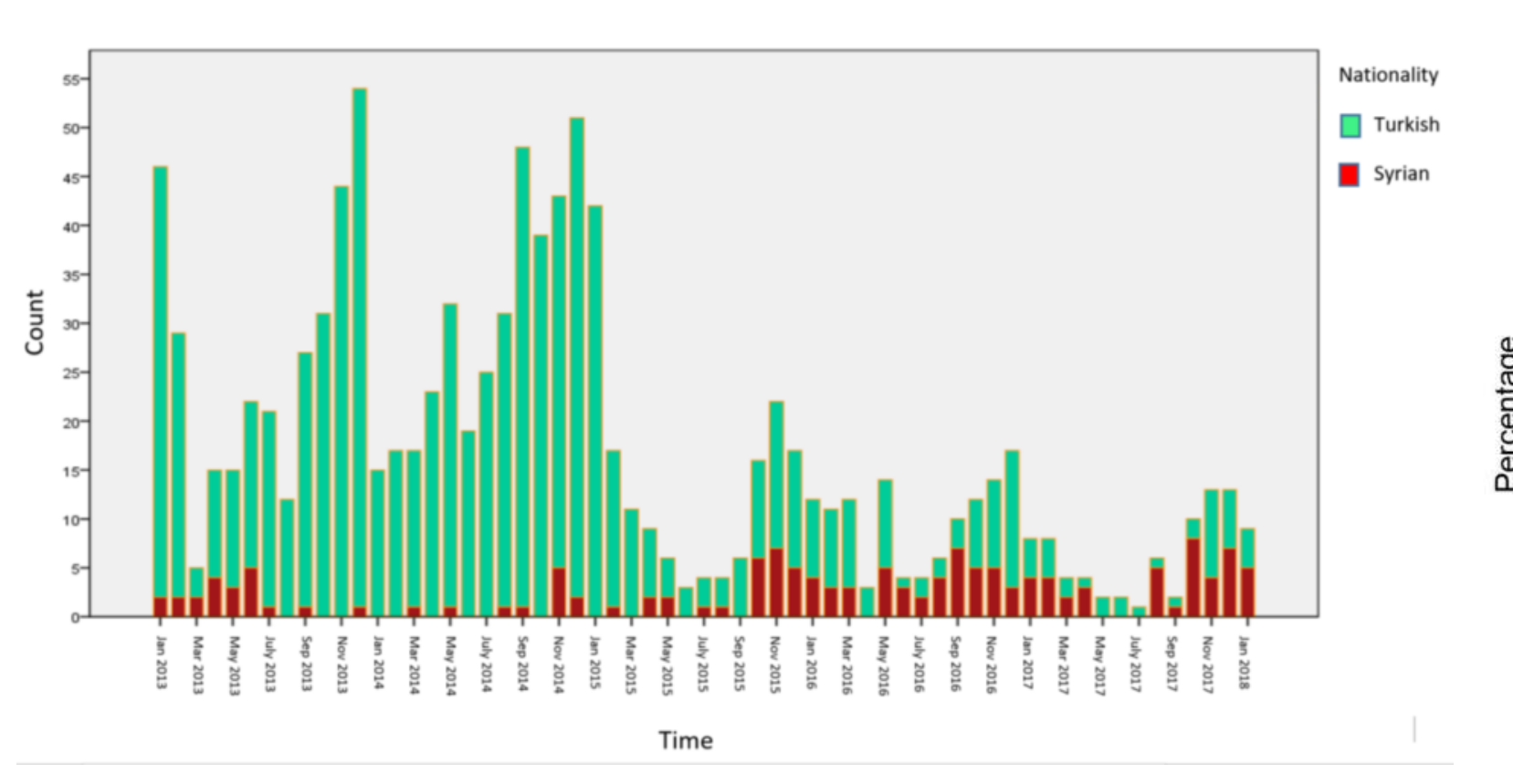

Figure 1. Distribution of cases by time and nationality

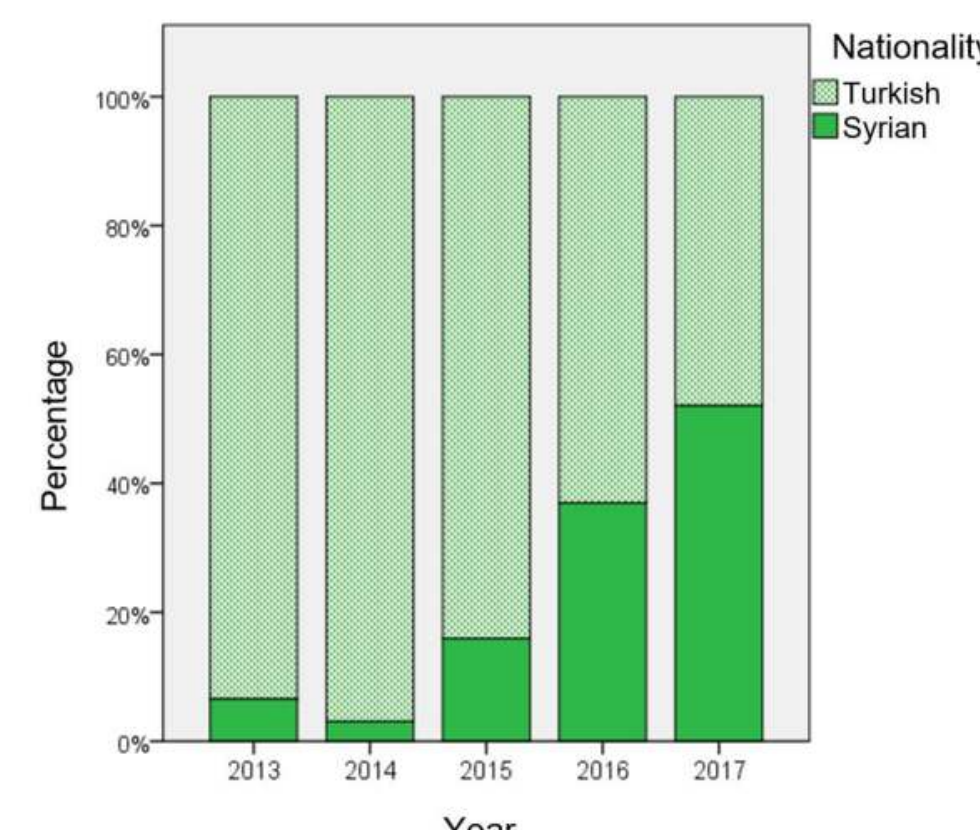

Figure 2. Percentage of cases by nationality

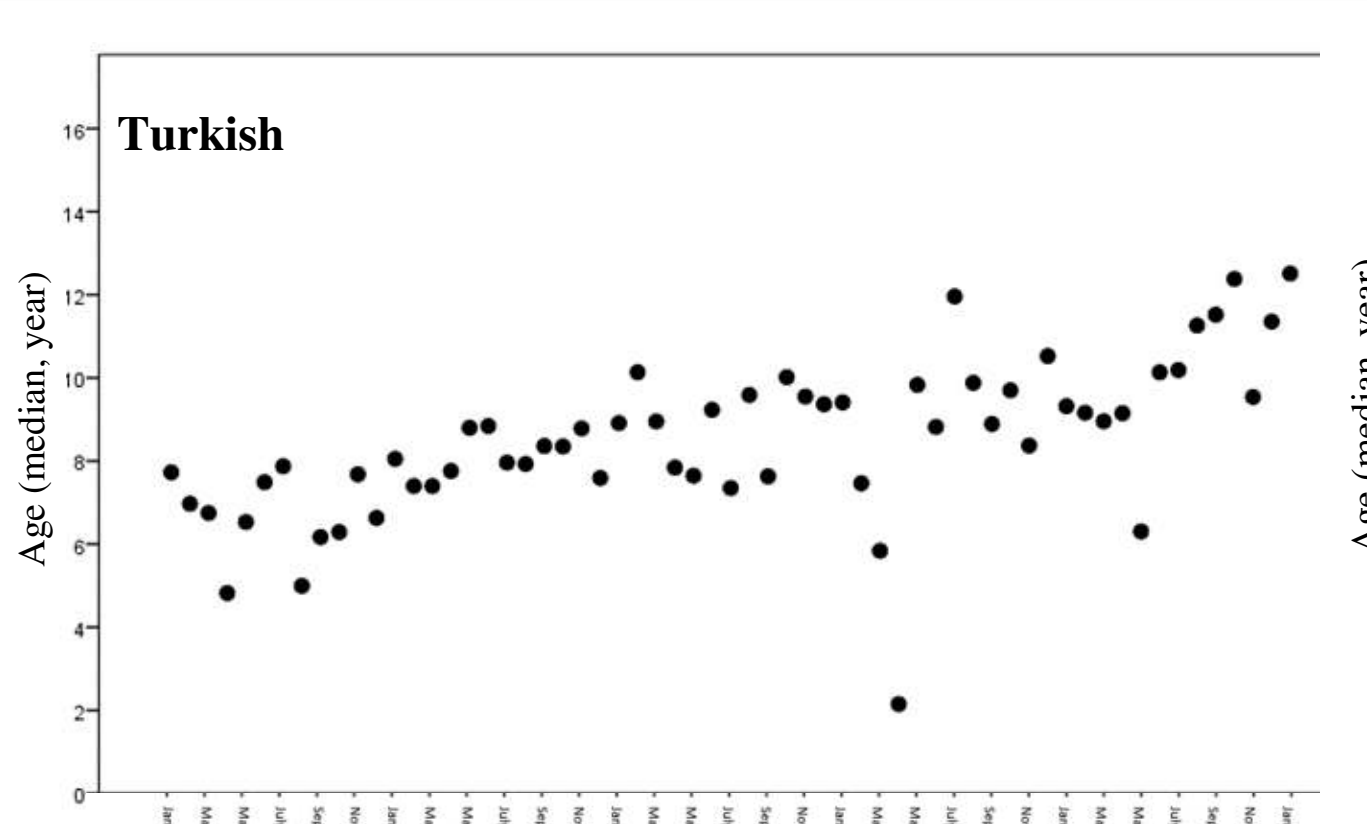

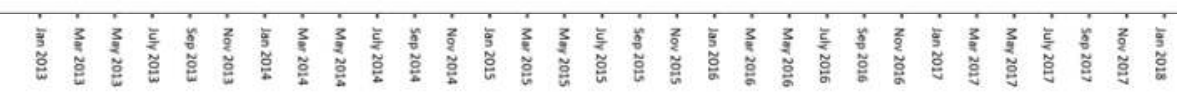

\section{Conclusions}

National vaccination of Hepatitis A markedly reduced the possible negative effect of mass migration. However, due to the presence of susceptible individuals in the community, the provision of high vaccination rates remains important. We think, monitoring epidemiological datas continuously and try to increase coverage of vaccination is neccessary for controlling infection.

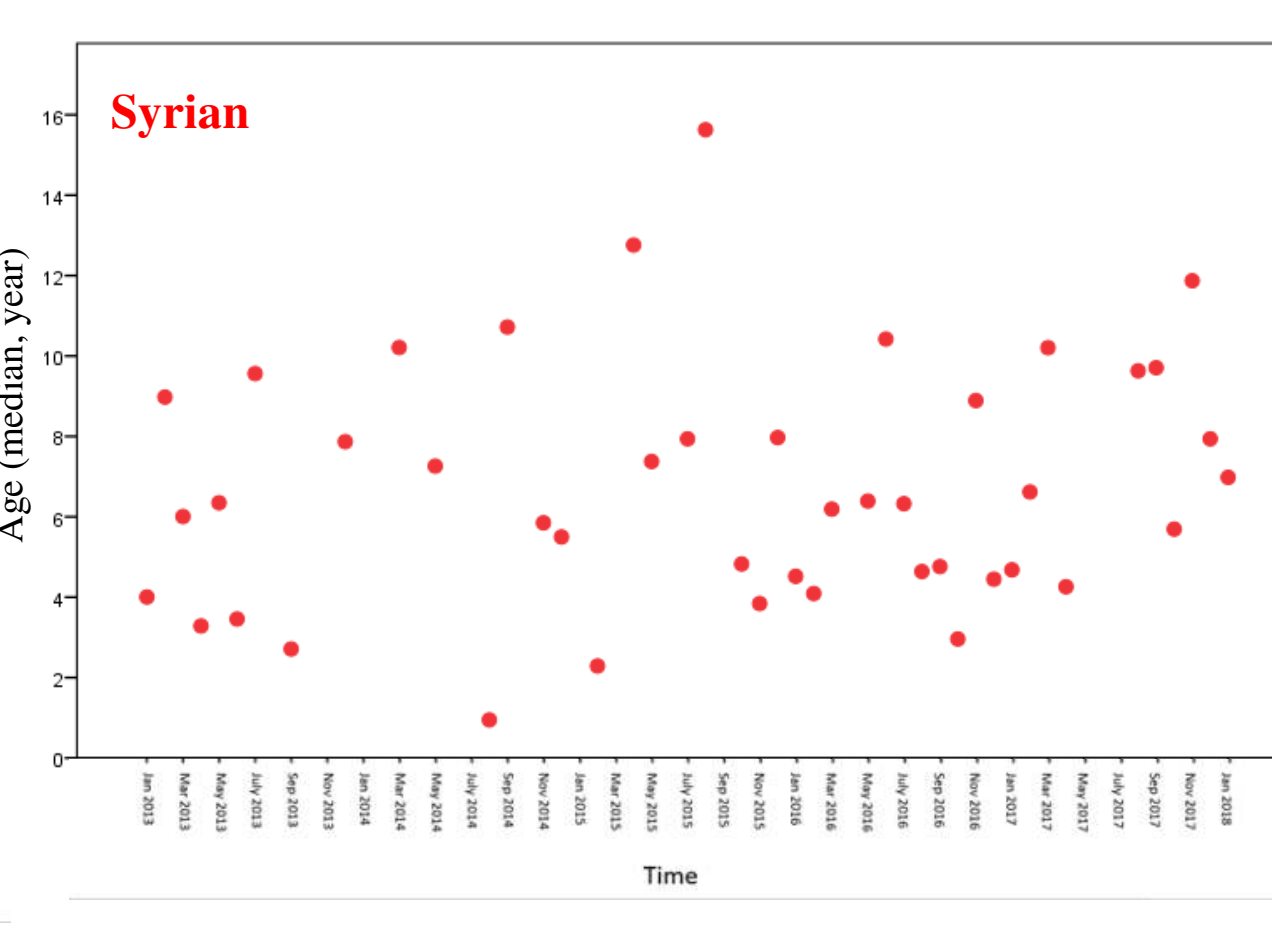

Figure 3. Age distrubition of the cases by time and nationality
References Kose S, Odemis I, Celik D et al. Hepatitis A, B, C and HIV seroprevalence
among Syrian refugee children admitted to outpatient clinics. Le Infezioni in

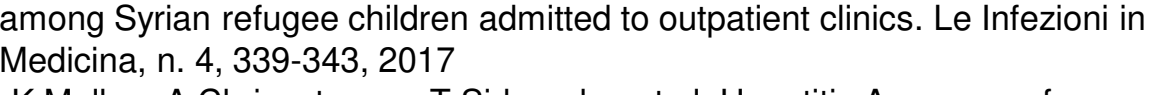
-K Mellou, A Chrisostomou, T Sideroglou et al. Hepatitis A among refugees,
asylum seekers and migrants living in hosting facilities, Greece, April to asylum seekers and migrants living in hosting facilities,
December 2016. Euro Surveill. 2017;222(4):pii 30448 . - Freidl GS, Tostmann A, Curvers M et al. Immunity against measles, mumps, ubella, varicella, diphtheria, tetanus, polio, hepatitis A and hepatitisis B among
adult asylum seekers in the Netherlands, 2016. Vaccine. 2018 Mar adult asylum seekers in 